\title{
Lofgren's Syndrome-Acute Onset Sarcoidosis and Polyarthralgia: A Case Report
}

\author{
Chan Woo Byun, MD, Seung Nam Yang, MD, Joon Shik Yoon, MD, Se Hwa Kim, MD
}

Department of Physical Medicine and Rehabilitation, Korea University Guro Hospital, Seoul, Korea

Lofgren's syndrome is an acute form of sarcoidosis characterized by erythema nodosum, bilateral hilar lymphadenopathy (BHL), and polyarthralgia or polyarthritis. This syndrome is common among Caucasians but rare in the Korean population. A 44-year-old woman was admitted to our hospital complaining of polyarthralgia. A chest radiograph revealed BHL and nodular shadows. Angiotensin-converting enzyme levels were within the normal range. Tissue biopsy from a mediastinum lymph node showed noncaseating granulomas. We diagnosed her with Lofgren's syndrome, an acute form of sarcoidosis.

Keywords Sarcoidosis, Arthritis, Lymph node

\section{INTRODUCTION}

Sarcoidosis is a multi-systemic granulomatous disease with an unknown etiology characterized by its pathological hallmark [1]. The lungs are the most frequently affected organ (>90\%), along with the skin, eyes, liver, and lymph nodes as other involved organs. Clinical features of joint involvement are found in $14 \%$ of cases at presentation and up to $38 \%$ during follow-up [2]. The frequency of muscle and bone involvement at presentation is low (1\%) at initial diagnosis but is found in 5\%-13\% of patients during follow-up [2]. One particular type of

Received April 17, 2012; Accepted June 27, 2012

Corresponding author: Seung Nam Yang

Department of Physical Medicine and Rehabilitation, Korea University Guro Hospital, 148 Gurodong-ro, Guro-gu, Seoul 152-703, Korea

Tel: +82-2-2626-1500, Fax: +82-2-859-5422, E-mail: snyang@dreamwiz. com

(c) This is an open-access article distributed under the terms of the Creative Commons Attribution Non-Commercial License (http://creativecommons. org/licenses/by-nc/3.0) which permits unrestricted noncommercial use, distribution, and reproduction in any medium, provided the original work is properly cited.

Copyright $\odot 2013$ by Korean Academy of Rehabilitation Medicine joint involvement is acute sarcoid arthritis (Lofgren's syndrome) which is described as a symmetric polyarthritis associated with hilar adenopathy with or without erythema nodosum (EN) [3]. Case reports of Lofgren's syndrome often describe women of Northern European, Irish, and Japan descent. To our knowledge, there has been only one report of Korean patients with Lofgren's syndrome, and most of their symptoms involved the skin [4]. We herein present a case of a 44-year-old woman with polyarthralgia who was diagnosed with Lofgren's syndrome.

\section{CASE REPORT}

A 44-year-old woman was admitted to our hospital in June 2011 complaining of arthralgia in both knees, elbows, and ankles. She had been diagnosed with hepatic cysts 10 years ago but was healthy before the appearance of bilateral polyarthritis of the knees 1 month before admission. She went to a nearby orthopedic clinic and reported temporary alleviation of the knee pain upon taking non-steroidal anti-inflammatory drugs (NSAIDs). 
Table 1. Laboratory findings on admission

\begin{tabular}{|c|c|}
\hline Complete blood count & \\
\hline White blood cell (/L) & 8,600 \\
\hline Neutrophils (\%) & 77.6 \\
\hline Eosinophils (\%) & 3.3 \\
\hline Monocytes (\%) & 7.3 \\
\hline Lymphocytes (\%) & 7.1 \\
\hline Hemoglobin (g/dL) & 11.4 \\
\hline Platelet (/L) & 290,000 \\
\hline \multicolumn{2}{|l|}{ Chemistry } \\
\hline Blood urea nitrogen (mg/dL) & 15.6 \\
\hline Creatinine (mg/dL) & 0.52 \\
\hline Uric acid (mg/dL) & 3.2 \\
\hline $\mathrm{Na}$ (sodium, mEq/L) & 138 \\
\hline $\mathrm{K}$ (potassium, mEq/L) & 5.0 \\
\hline $\mathrm{Cl}$ (chloride, $\mathrm{mEq} / \mathrm{L}$ ) & 106 \\
\hline $\mathrm{Ca}$ (calcium, mg/dL) & 9.5 \\
\hline Protein $(\mathrm{g} / \mathrm{dL})$ & 7.2 \\
\hline $\operatorname{Albumin}(\mathrm{g} / \mathrm{dL})$ & 4.2 \\
\hline Aspartate aminotransferase (IU/L) & 37 \\
\hline Alanine aminotransferase (IU/L) & 60 \\
\hline Alkaline phosphatase (IU/L) & 67 \\
\hline Glucose (mg/dL) & 101 \\
\hline Antistreptolysin-O (U/mL) & 79 \\
\hline Free thyroxine (ng/dL) & 1.35 \\
\hline Triiodothyronine (ng/mL) & 1.28 \\
\hline $\begin{array}{l}\text { Thyroid stimulating hormone (uIU/ } \\
\mathrm{mL} \text { ) }\end{array}$ & 0.75 \\
\hline \multicolumn{2}{|l|}{ Serology } \\
\hline Rheumatoid factor $(\mathrm{U} / \mathrm{mL})$ & $<3$ \\
\hline $\mathrm{C} 3(\mathrm{mg} / \mathrm{dL})$ & 144 \\
\hline $\mathrm{C} 4(\mathrm{mg} / \mathrm{dL})$ & 34 \\
\hline Anti-nuclear antibodies & $1: 80$ \\
\hline dsDNA Ab (IU/mL) & 2.5 \\
\hline Anti-CCP Ab (U/mL) & $<25$ \\
\hline Angiotensin converting enzyme (U/L) & 29 \\
\hline \multicolumn{2}{|l|}{ Erythrocyte sedimentation rate $(\mathrm{mm} / \mathrm{hr})$} \\
\hline On admission & 39 \\
\hline 2 week later & 12 \\
\hline \multicolumn{2}{|l|}{ C-reactive protein (mg/dL) } \\
\hline On admission & 45.79 \\
\hline 2 week later & 4.96 \\
\hline
\end{tabular}

$\mathrm{C} 3$, third components of complement; $\mathrm{C} 4$, fourth components of complement; dsDNA Ab, double-stranded DNA antibody; Anti-CCP Ab, anti-cyclic citrullinated protein antibody.
A physical examination showed mild swelling and tenderness in both ankles without limitation of range of motion. Laboratory studies showed elevated erythrocyte sedimentation rate (ESR, $39 \mathrm{~mm} / \mathrm{hr}$ ) and C-reactive protein level (CRP, $45.79 \mathrm{mg} / \mathrm{L}$ ) (Table 1). White blood cell count was $8,600 / \mathrm{L}$, blood hemoglobin was slightly low at $11.4 \mathrm{~g} / \mathrm{dL}$, and platelet count was $290,000 / \mathrm{L}$. The serum angiotensin-converting enzyme (ACE) level was (29.0 IU/ L; normal range, 7.7-29.4 IU/L). Aspartate aminotransferase (AST) and alanine transaminase (ALT) levels were slightly high at $37 \mathrm{IU} / \mathrm{L}$ and $60 \mathrm{IU} / \mathrm{L}$, respectively. She was negative for rheumatoid factor and anti-cyclic citrullinated peptide (anti-CCP) antibody. Her C3 level was $144 \mathrm{mg} / \mathrm{dL}, \mathrm{C} 4$ was $34 \mathrm{mg} / \mathrm{dL}$, and antinuclear antibody was positive at a titer of 1:80 (homogeneous and fine cytoplasmic granules pattern), but specific antibodies were not detected (Table 1).

Knee, ankle, hip, and hand X-ray findings showed periarticular osteoporosis (Fig. 1). Ultrasonography findings suggested polyarticular inflammatory synovitis of both knees, elbows, ankles, with a combined partial tear of common extensor tendons in both elbows.

Chest X-ray findings showed focal mediastinal widening in both the hilum and the right upper trachea (Fig. 2A), and chest computed tomography scan indicated multiple enlarged lymph nodes of the mediastinum and both hila (Fig. 2B). The bone scan showed mildly increased uptake in bilateral hands, wrists, and other small joint areas (Fig. $3)$.

A mediastinoscopic lymph node biopsy was performed. The obtained tissues of mediastinal lymph nodes showed noncaseating granuloma of epithelioid cells and the presence of giant cells (Fig. 4).

Based on the bilateral hilar lymphadenopathy (BHL) with polyarthralgia, the patient was diagnosed with Lofgren's syndrome, although EN. NSAID treatment did not alleviate her symptoms for 1 week. Oral administration of prednisolone (10 mg/day) was initiated. The pain resolved within 1 week, and the levels of ESR and CRP were normalized after 2 weeks ( $12 \mathrm{~mm} / \mathrm{hr}, 4.96 \mathrm{mg} / \mathrm{L})$. The prednisolone dose was lowered 1 month later $(5 \mathrm{mg} /$ day). The pain and joint swelling were improved, but she sometimes felt mild pain in the joints, and BHL was still seen on simple chest radiography after 2 months. For these reasons, prednisolone administration has been continued for 8 months until now. No recurrence has 

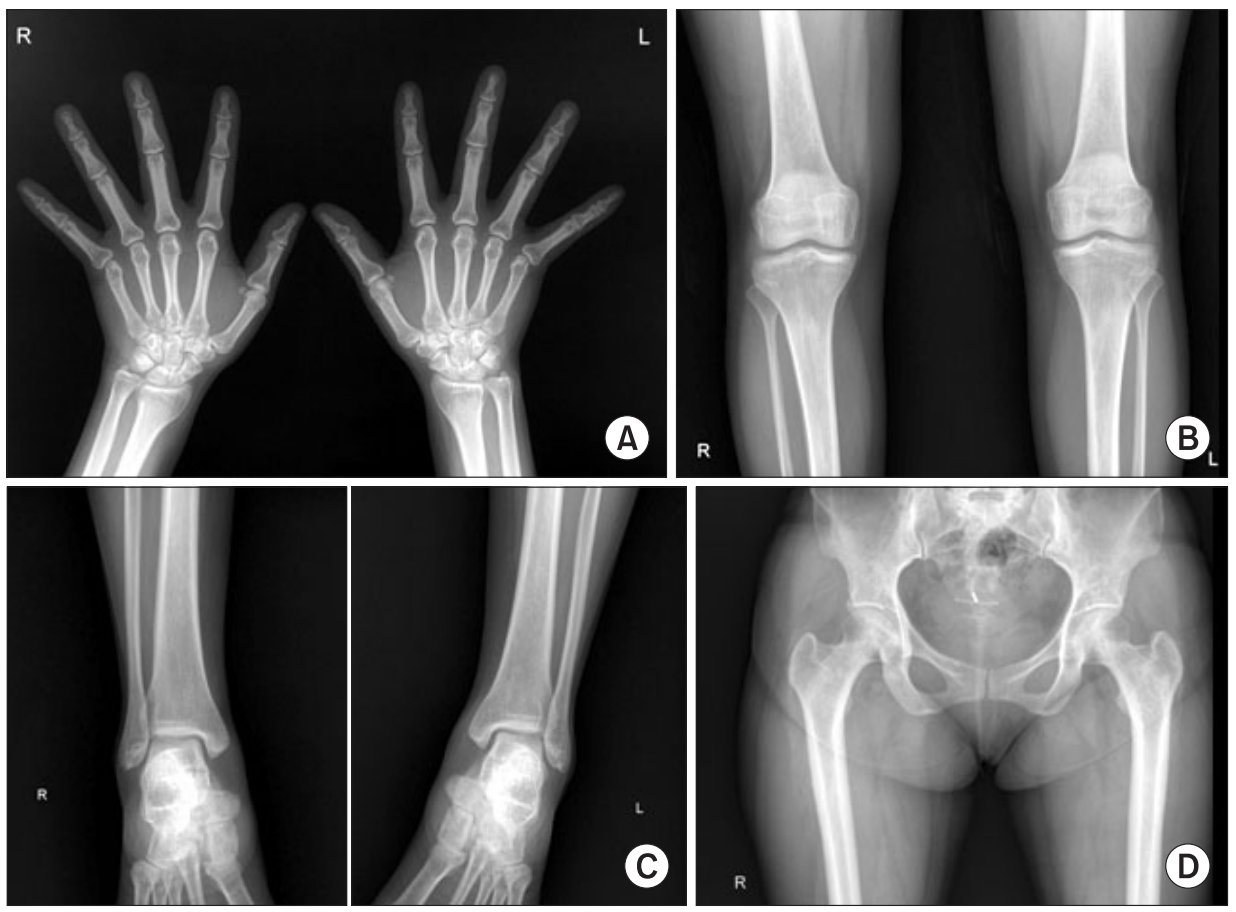

Fig. 1. Simple radiography of (A) bilateral hands, (B) knees, (C) ankles, and (D) hip showed periarticular osteoporosis. There is no swelling or any other abnormal findings.
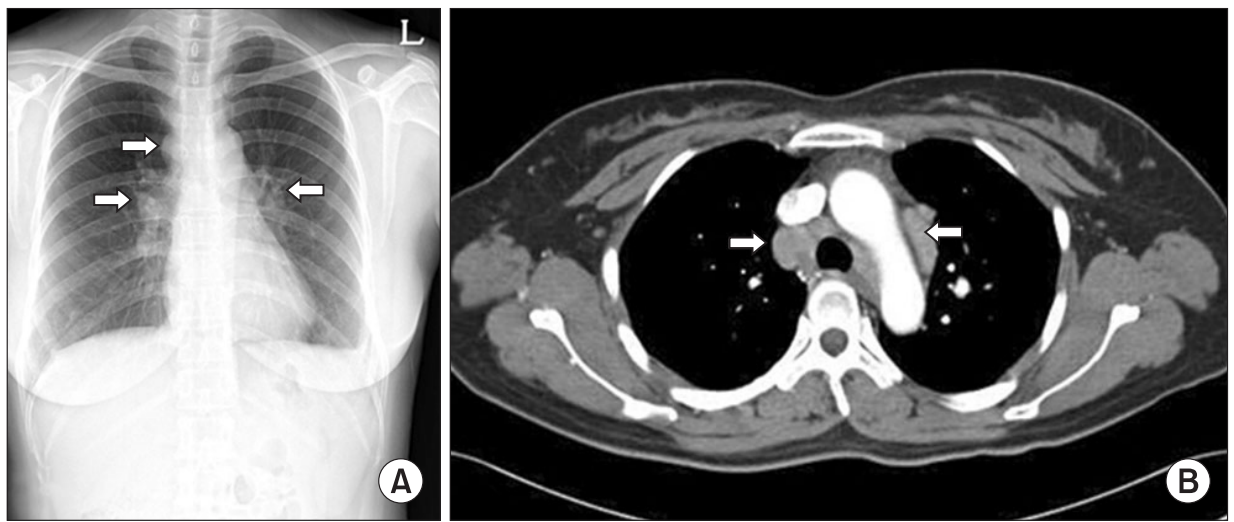

Fig. 2. (A) Simple chest radiography showed mediastinal widening in both hila and in the upper right trachea (arrows). (B) Chest computerized tomography showed multiple enlarged lymph nodes in the mediastinum and in both hilar areas (arrows).

been observed since then.

\section{DISCUSSION}

While sarcoidosis occurs worldwide, higher annual incidence rates have been reported among United States Blacks, the Irish, and Scandinavians [1]. On the basis of cumulative incidence estimates, the lifetime risk of sarcoidosis for United States Blacks is $2.4 \%$ and that for United States Whites $0.85 \%$ [1]. In Korea, sarcoidosis is a rare disease with the incidence rate being 0.125 per 100,000 and Lofgren's syndrome is even more rarely reported $[4,5]$.

Acute polyarthritis occurs in $10 \%$ to $39 \%$ of patients with sarcoidosis, particularly in the early phases of the disease, which could be the presenting feature. BHL is almost invariably present in patients with acute sarcoid arthritis; fever and EN are present in $90 \%$ and $60 \%$ of the cases, respectively $[6,7]$.

In 1953, Lofgren characterized 212 adult patients of BHL who were practically regarded as having sarcoidosis based on the absence of tuberculosis. Lofgren demonstrated that EN was present at the onset of the disease in 113 cases in which articular symptoms were common (101 cases, $89 \%)$. There was either pain only in the joints $(20 \%)$, or pain accompanied by swelling (69\%) [8].

Arthritis in sarcoidosis is usually symmetrical; the ankles are involved in more than $90 \%$ of the cases; the knees, small joints of the hands or feet, wrists, and elbows are involved in $15 \%$ to $40 \%[5,7,9]$. Local pain, soft- 
tissue swelling, periarticular tenderness, edema, and joint effusion may be present [6]. Radiographs are normal or reveal only soft-tissue swelling [6]. ESR or CRP level is elevated in $>80 \%$ of patients with acute sarcoid polyarthritis $[6,7]$. Serum ACE level is usually increased, and rheumatoid factor is negative. Synovial fluid in sarcoid arthritis reveals lymphocytosis and elevated protein levels $[6,7]$.

Diagnosis of Lofgren's syndrome is not complicated but straightforward when the characteristic triad (BHL, polyarthritis, and EN) is present. Nevertheless, the disease

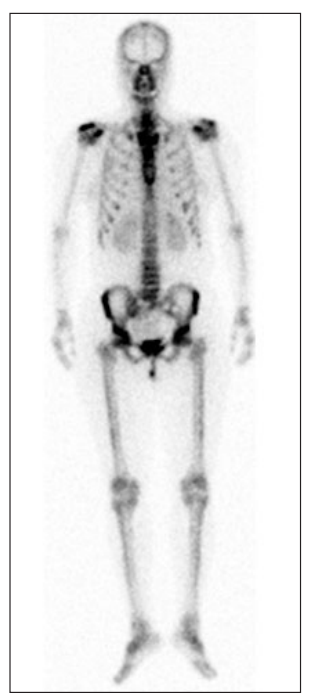

Fig. 3. Bone scintigraphy showed mildly increased uptakes in bilateral hands, wrist, shoulders, and small joint areas. may be somewhat difficult to diagnose because variant forms of this syndrome are often observed. In addition, uveitis and elevated levels of ACE, although useful clues for diagnosing sarcoidosis, are often absent in patients with Lofgren's syndrome (eye involvement, 5\%; elevated ACE levels, 50\%) [9].

Lofgren's syndrome is described as a symmetric polyarthritis associated with hilar adenopathy with or without EN. Regarding the case described herein, the patient showed polyarthritis, but not EN. Among 49 patients studied by Gran et el. [3], all patients had peripheral arthritis and hilar adenopathy, and $87.8 \%$ presented with EN. Sato et al. [10] summarized the reported 13 patients of Lofgren's syndrome in Japan. BHL was observed in almost all patients (85\%), but EN was not observed in $38 \%$ of the patients. These facts underscore the difficulty of diagnosing Lofgren's syndrome. Biopsy must be done for differential diagnosis. Because peripheral lymphadenopathy was not found in this patient, biopsy of the lymph nodes by mediastinoscopy was necessary to support the diagnosis of sarcoidosis.

Lofgren's syndrome was regarded as a self-limiting disease that is generally resolved within the first year, with the mean duration ranging from 3 weeks to 3.7 months $[3,9]$. However, $8 \%$ of patients had active symptoms two years after the onset; $6 \%$ had episodes of recurrent sarcoidosis 2-20 years after the diagnosis [8]. NSAIDs or colchicine may be effective for mild cases. For more severe cases, oral corticosteroids are warranted [7]. In the
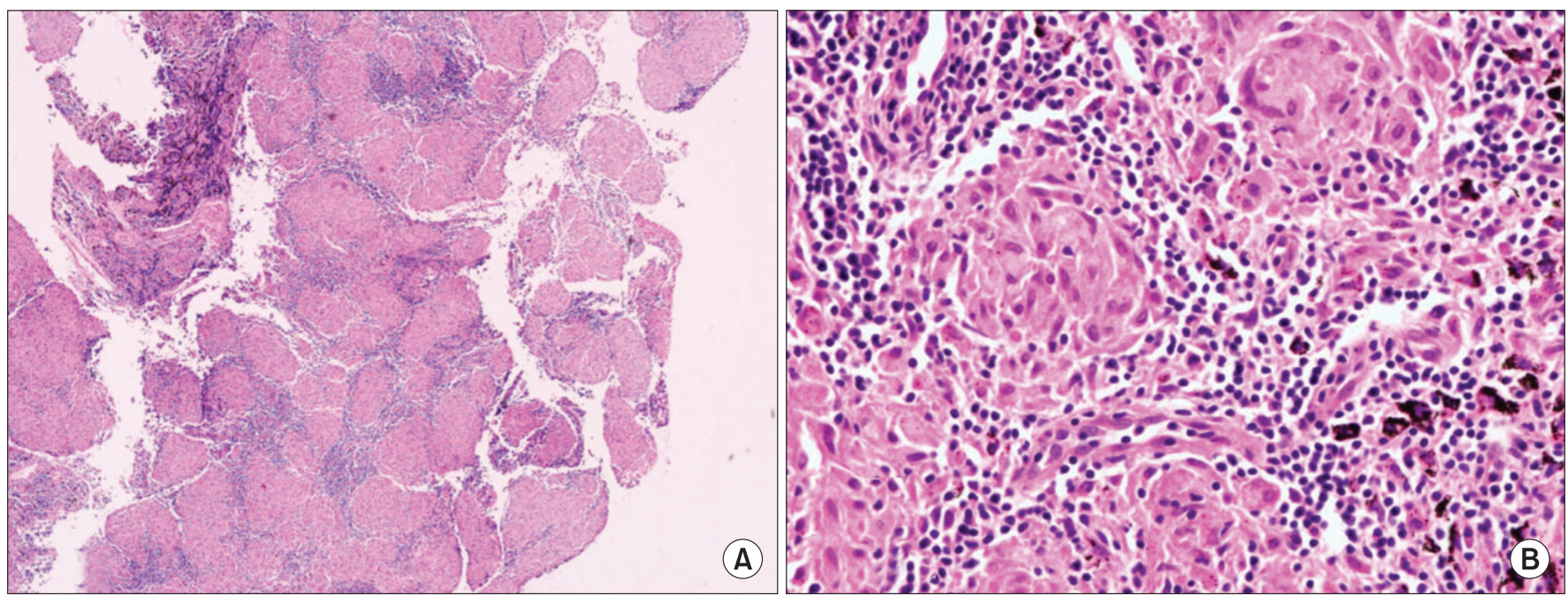

Fig. 4. A biopsied mediastinal lymph node treated using hematoxylin and eosin stain showed noncaseating granuloma of epithelioid cells with multinucleated giant cells (A, ×40; B, ×400). 
present patient, acute manifestations of the musculoskeletal symptoms were refractory to NSAIDs initially but responded quickly to the later administration of prednisolone. The patient's CRP and ESR levels were normalized, showing a favorable therapeutic effect for Lofgren's syndrome.

Polyarthralgia and EN are often observed in various collagen diseases, including rheumatoid arthritis. Thus, Lofgren's syndrome, an acute form of sarcoidosis, must be differentially diagnosed. It is also noteworthy that, in Korean patients with Lofgren's syndrome, the characteristic triad is not always present. Biopsy from skin rash, lung nodules or lymph nodes should be considered in order to reach an early and precise diagnosis.

\section{CONFLICT OF INTEREST}

No potential conflict of interest relevant to this article was reported.

\section{REFERENCES}

1. Newman LS, Rose CS, Maier LA. Sarcoidosis. N Engl J Med 1997;336:1224-34.

2. Jansen T, Geusens P. Sarcoidosis: joint, muscle and bone involvement. Eur Respir Monogr 2005;32:210-9.

3. Gran JT, Bohmer E. Acute sarcoid arthritis: a favourable outcome? a retrospective survey of 49 patients with review of the literature. Scand J Rheumatol 1996;25:70-3.

4. Yang SG, Suh DH, Cho KH. A case of Lofgren' s syndrome. Korean J Dermatol 1995;33:931-4.

5. Kang EH. Sarcoidosis in Korea: revisited. J Korean Med Assoc 2008;51:925-32.

6. James DG, Neville E, Carstairs LS. Bone and joint sarcoidosis. Semin Arthritis Rheum 1976;6:53-81.

7. Zisman DA, Shorr AF, Lynch JP 3rd. Sarcoidosis involving the musculoskeletal system. Semin Respir Crit Care Med 2002;23:555-70.

8. Lofgren S, Lundback H. The bilateral hilar lymphoma syndrome; a study of the relation to tuberculosis and sarcoidosis in 212 cases. Acta Med Scand 1952;142:265-73.

9. Mana J, Gormez-Vaquero C, Montero A, Salazar A, Marcoval J, Valverde J, et al. Lofgren's syndrome revisited: a study of 186 patients. Am J Med 1999;107:240-5.

10. Sato T, Tsuru T, Hagiwara K, Miyashita K, Matsuno H, Goto A, et al. Sarcoidosis with acute recurrent polyarthritis and hypercalcemia. Intern Med 2006;45:363-8. 